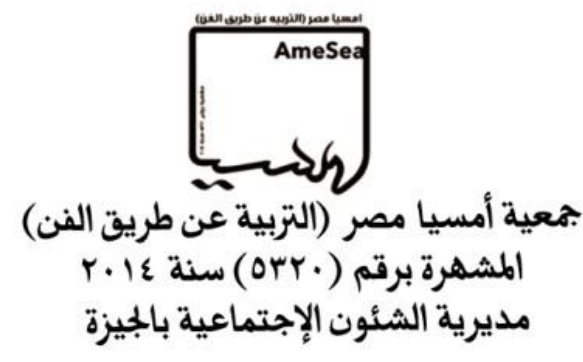

\title{
عنوان البحث
}

تحقيق نسجيات يدوية مرسمة لمناظر طبيعية باسلوب مدرسة الباربيزون

إعداد : تهاني سامي كلكتاوي

الدحاضر بكلية التصاميم

جامعة الملك عبد العزيز 
يعتبر نسيج اللحمات غير الممتدة " تابستري" Tapestry من المنسوجات التي استخدمت منذ القدم وهذا

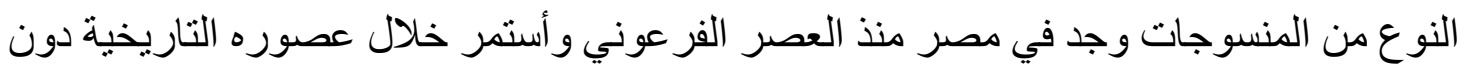
انقطاع، وقد بلغ الفر اعنة شأناً عظيماً في نسج هذا النوع من المنسوجات الذي استمر في تطوير مستمر

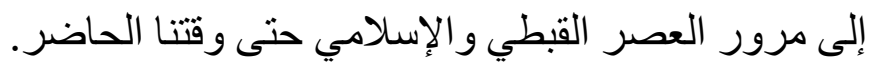

و نفذت كثير من الأعمال الفنية التشخيصية و التعبيرية عن طريق التصميم النسجي كما في الجوبلان

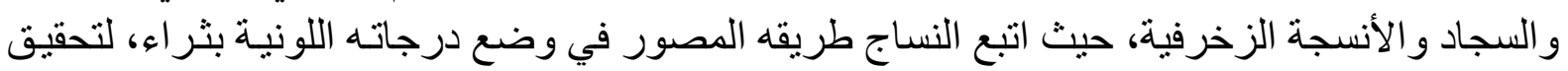

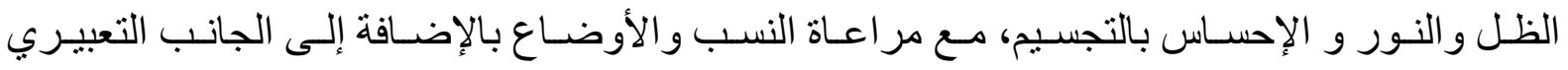
واستخدام المنظور و الحركة في التصميم.

ويعتبر نسيج "التابستري" من التقنيات التي أتاحت تأثثر ات فنية و اضحة لمحاكاة الطبيعة حيث

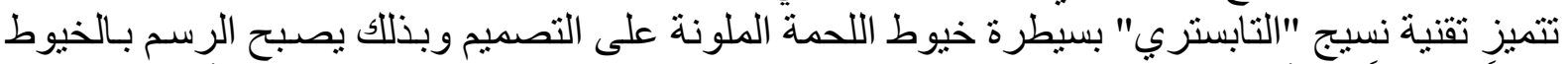

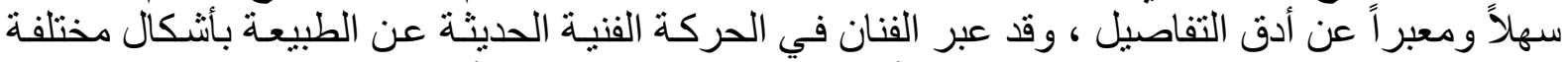

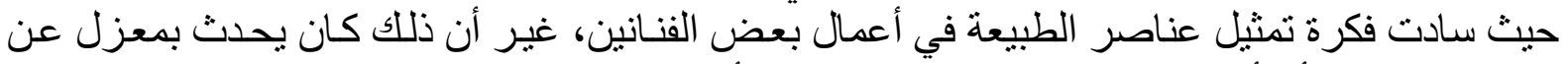

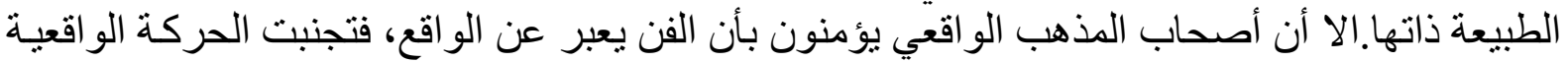

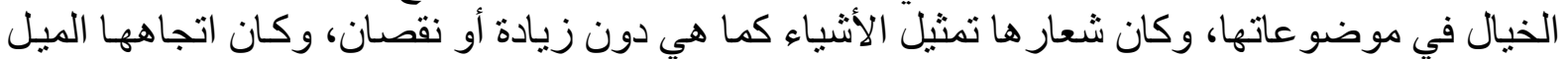

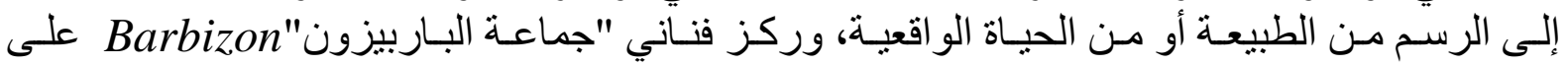

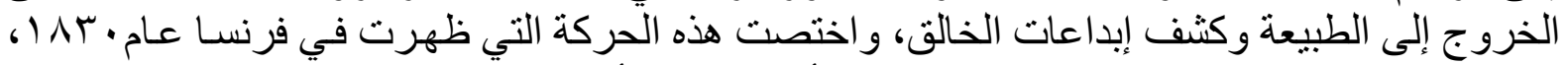

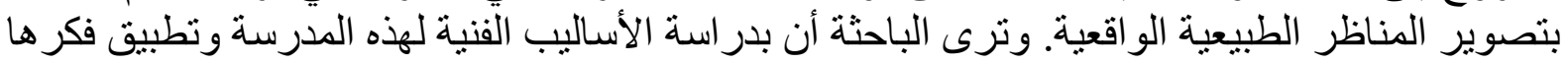

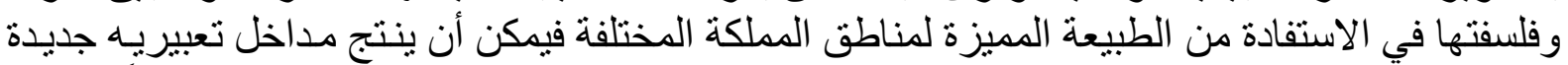

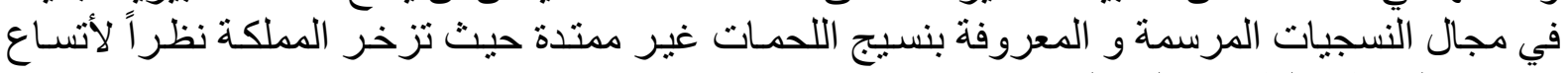

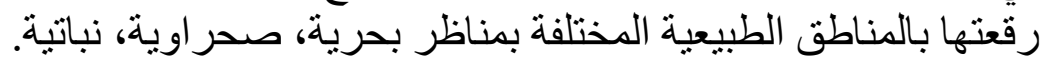

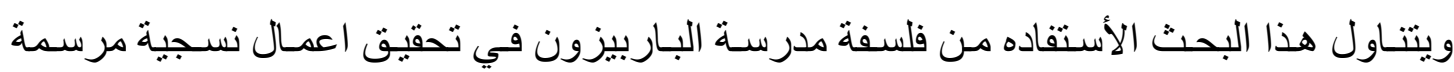
مستلهمه من الطبيعة السعودية. مشكلة البحث:

تتركز مشكلة البحث في إمكانية المزاوجة بين فكر وفلسفة أسلوب جماعة "الباربيزون" و النسجيات المرسمة الذي لاز ال يستخدم بنفس الأساليب التقليدية مع إضافة الإمكانات و التقنيات الحديثة

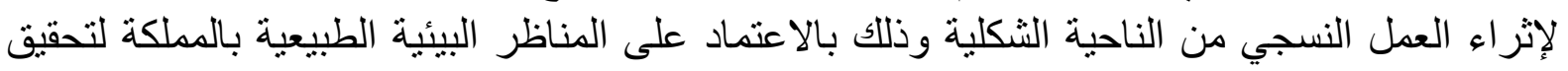

وتتلخص تساؤلات البحث فيما يلي:-

( ) هل يمكن استخلاص مداخل تعبيرية جديدة من خلال در اسة جماعة "الباربيزون" Barbizon

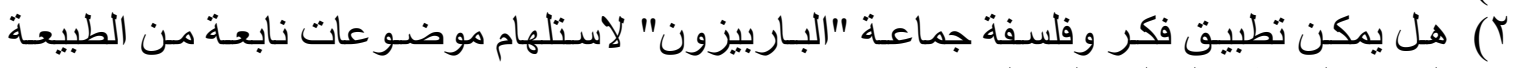

المميزة لمناطق المملكة المختلفة ؟

ץ) هل يمكن الاستفادة من تلك المداخل في ابتكار تصميمات نسـية تصلح لأسلوب اللحمـات غير المتدة؛ 
يمكن تحقيق تصميمات نسجيه مرسمة جديدة من خلال اسلوب جماعة "الباربيزون" Barbizon مستمدة

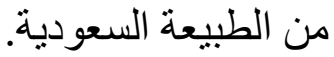

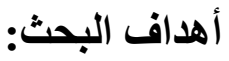

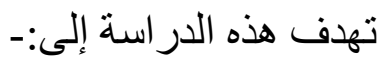

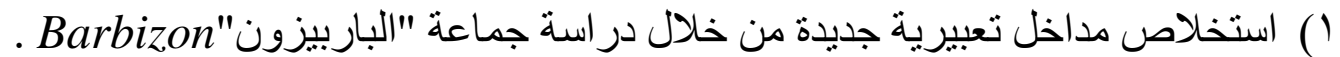

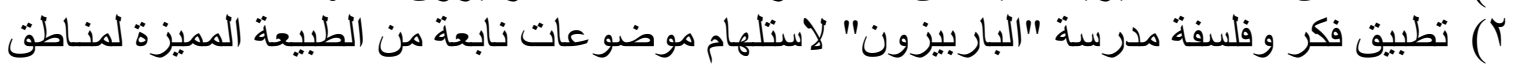
المملكة المختلفة.

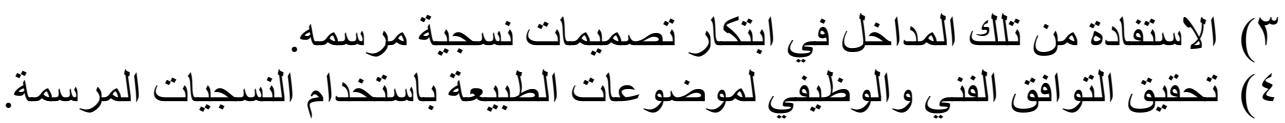

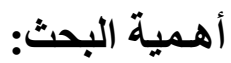

( ) دعم روح الانتمـاء للوطن من خـلال تصميم نسجيات تحمل رموز اً شكلية تعبر عن الطبيعـة

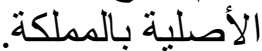
r) الاستفادة من تراث النسيج اليدوي وتنمية الفكر الإبتكاري في مجالات جديدة.

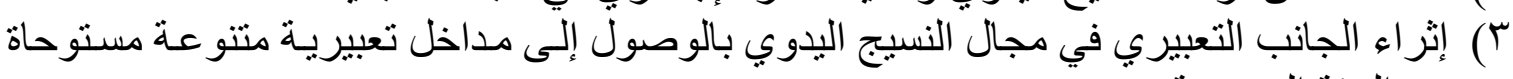
من البيئة السعودية. ؛) إتاحة فرص التجريب المرتبطة بالإبداع في مجال التصميمات النسجية كأحد الأنشطة التربوية الهامة. 0) المسـاهمة في تنميـة الحس الجمـالي لدى أفر اد المجتمع عن طريق النسـيات المستوحاة مـن الطبيعة في المملكة.

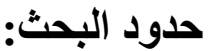

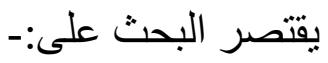

( ) الموضو عات التي تنتمي للبيئة الطبيعية في المملكة العربية السعودية.

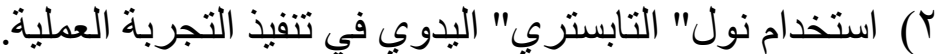
r) تناول أسلوب جماعة "الباربيزون" Barbizon باستخدام أسلوب اللحمات غير الممتده.

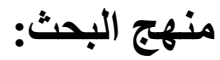

يتبع الدراسة الدنهج الوصفي التحليلي في دراسة النسيج المرسم، كما تتبع المنهج التجربي في تحقيق المداخل التشكيلية في التجربة العملية للباحثة. أ- بركز البحث في إطاره النظري على النقاط النالية:-

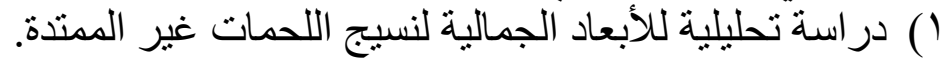

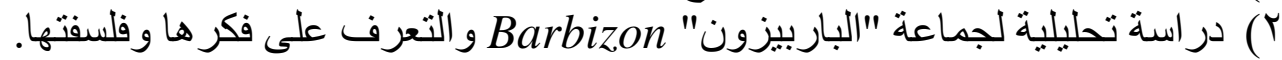
r) در اسة وصفيه للمناطق الطبيعية المتنو عة للمملكة العربية السعودية. 
ب- يتركز الإطار العملي في هذا البحث على:تطبيق الفكر المميز لجماعة" الباربيزون" فئر البئ إنتاج نسجيات تعبر عن المملكة باستخدام أسلوب اللحمات

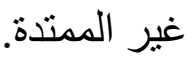

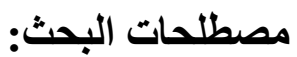

النسجيات المرسمة "نسيج اللحمات غير المثندة": (Unextended Weft):-

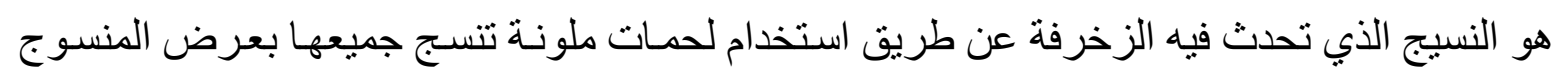
(أي لا تصل من البر سل الأيمن إلى البرسل الأيسر) كما في باقي المنسوجات بل النس تنسج فقط في المكان

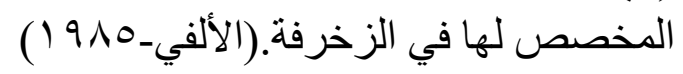

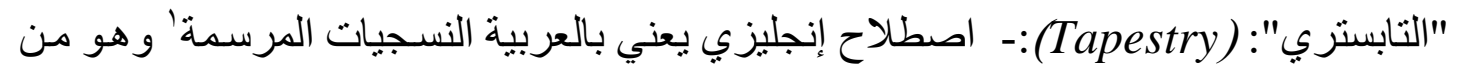

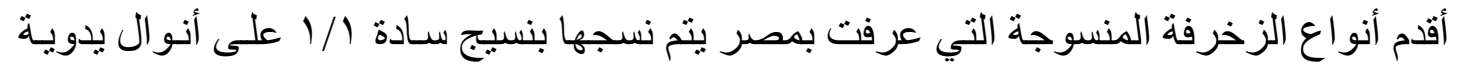
وفيه تغطى اللحمات الملونة خيوط السدا بالكامل بحيث تظهر على على شكل تضليعات طويلة فقط.

$$
\text { (صبري-19V0) }
$$

أسنان المشط (Comb-Tooth):-

يطلق هذا المصطلح على طريقة وصل اللحمات الملونة في نسيج القباطي بعضها ببعض تلاقيا لوجود

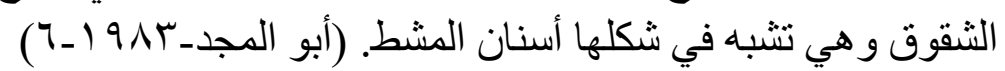

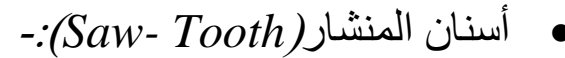

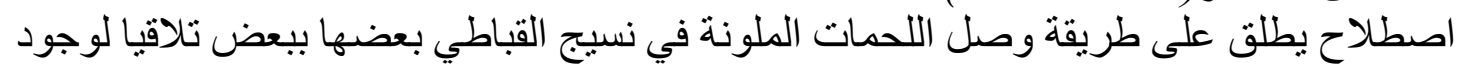

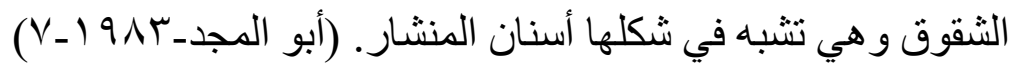

المدرسة الو اقعية جماعة "الباربيزون"( Barbizon):-

تهدف هذه المدرسة إلى تمثيل الأثياء كما هي دون زيادة أو نقصان، وكان اتجاهها الميل إلى الرسم من

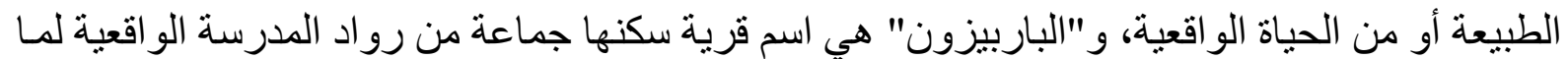

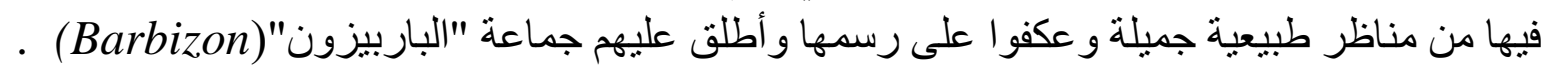
الأطار النظري:

النسجيات اليدوية المرسمة:

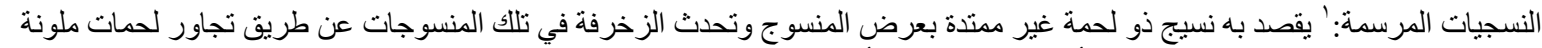

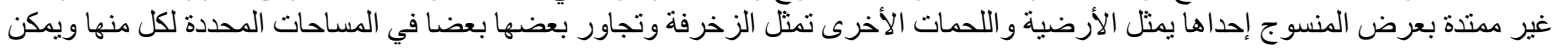


النسـيات اليدويـة المرسـة تســى نسيج اللحمـات غيـر المـتـدة " تابسـتري" Tapestry وقد

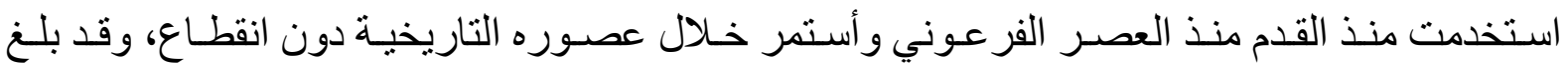
الفر اعنة شأناً عظيماً في نسج هذا النوع من المنسوجات الذي استمر في تطوير مستمر إلى مرور العصر

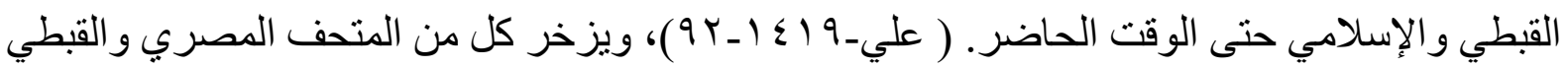

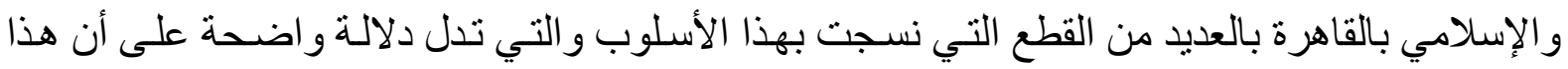

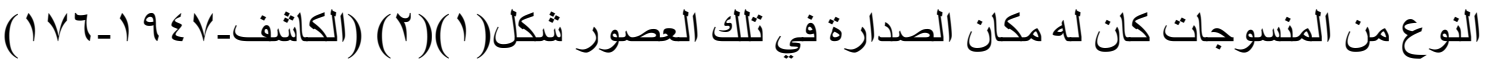

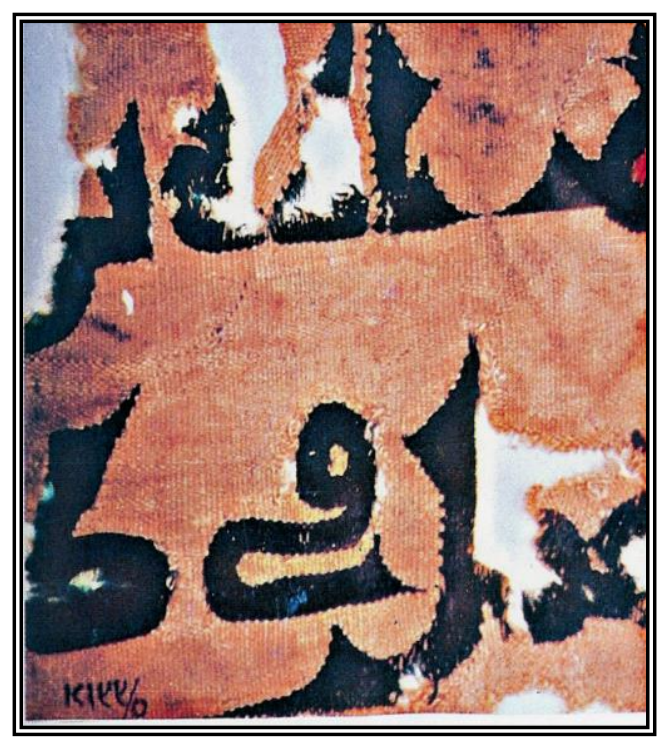

شكل(ץ) قطعة نسيج من العصر الإسلامي.

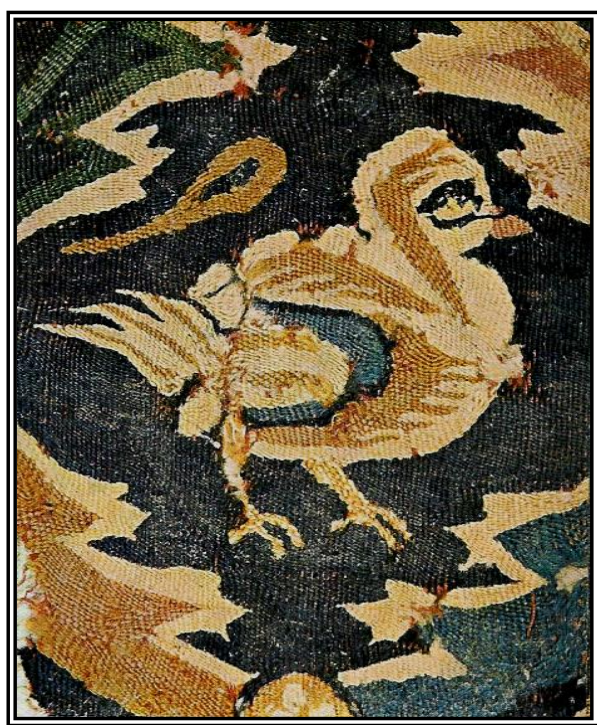

شكل(1 ) قطعة نسيج من العصر القبطي.

وقد أطلق على النسيج المرسم او نسيج اللحمات غير الممتدة العديد من التسميات التي ارتبطت

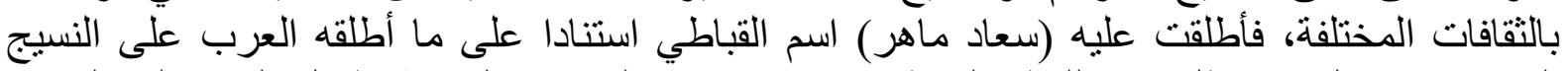

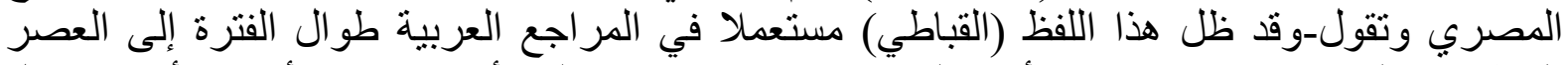

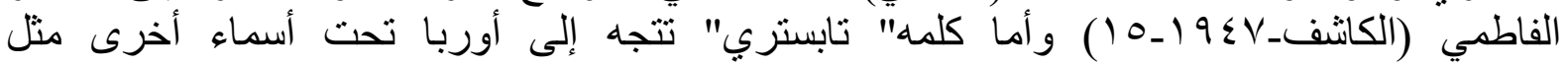

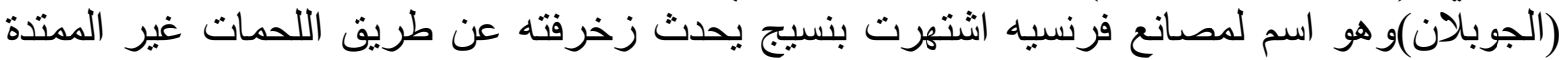

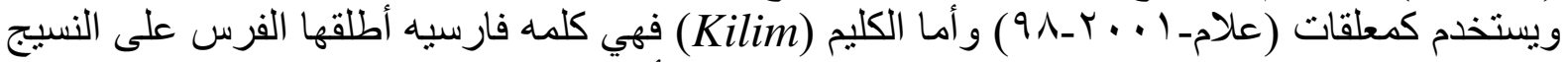
المصنوع بطريقه اللحمات الملونة غير الممتدة كما سماها أهل تركستان جيلام (Giylam) ومعناه ذوناه

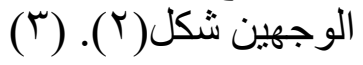




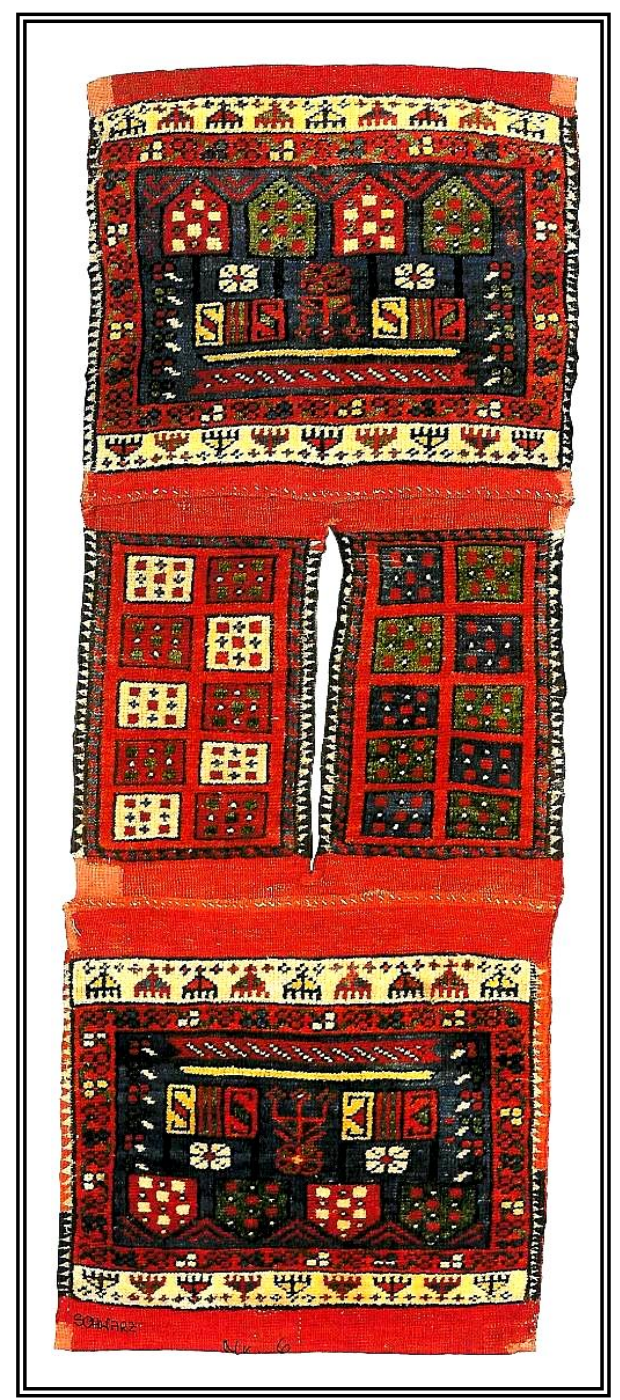

$$
\text { شكل (Y) منسوجة من الكليم بتركيا عن }
$$

)K.Zipper \& C.Fritzsche:ORIENTAL RUGS,Volume4, TURKISE.(

ومن أهم مميز ات النسيج المرسم شكل (ع)

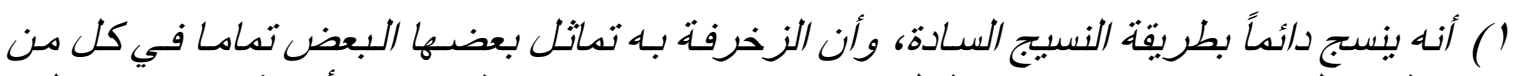

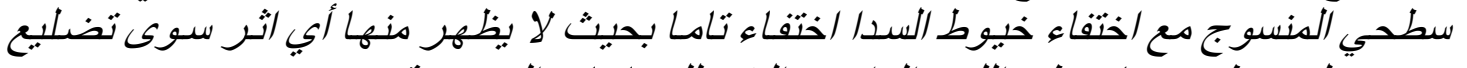

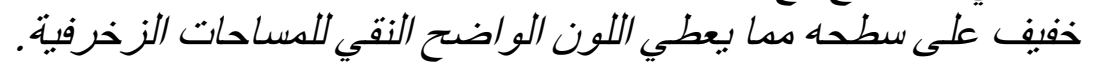

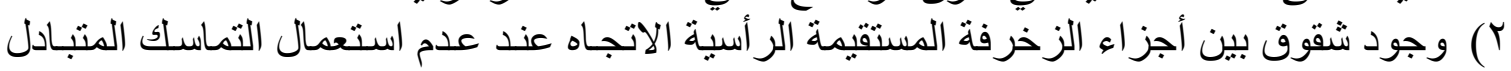
بين اللونين المتجاورين.

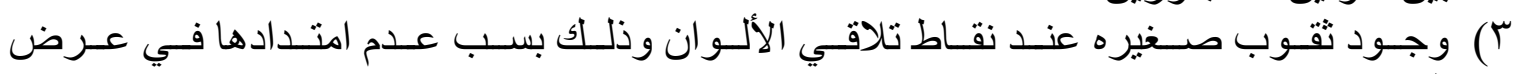

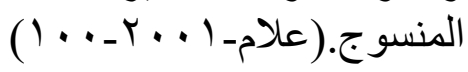




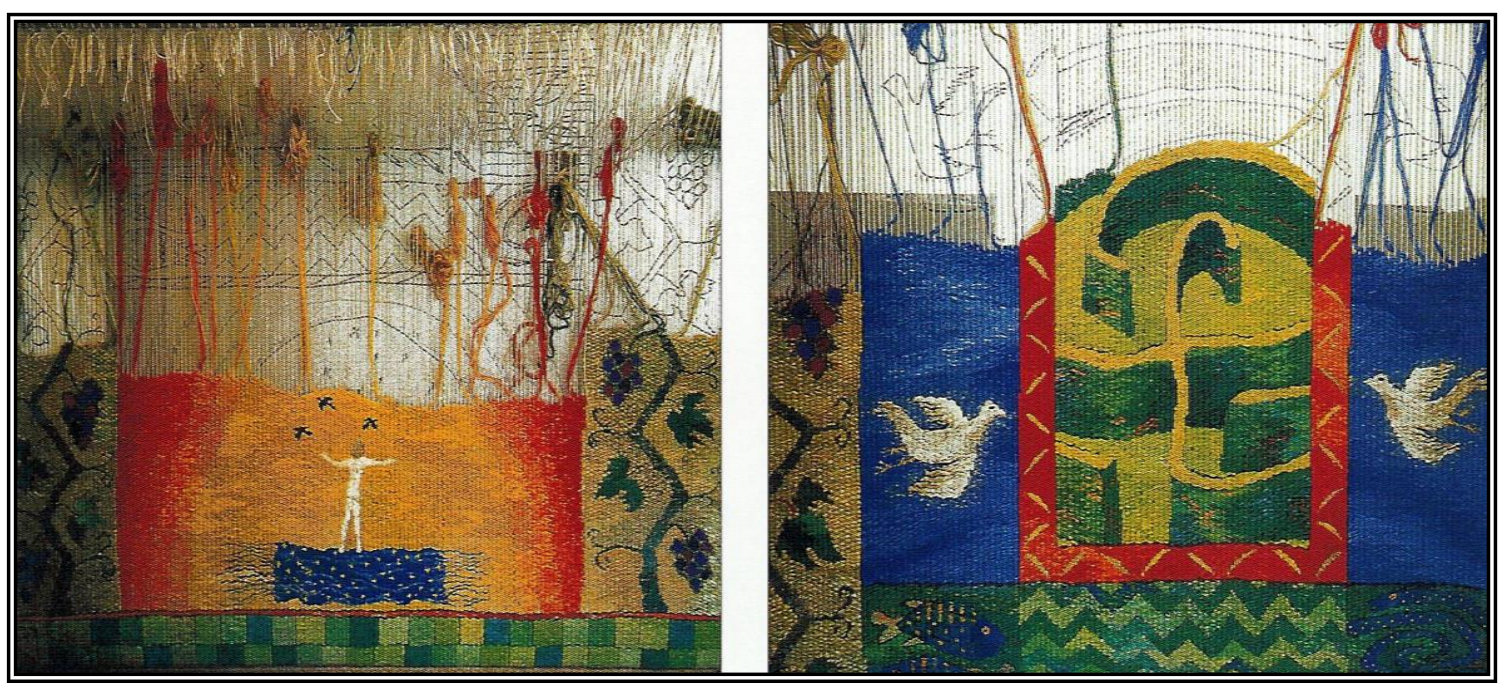

شكل (ع) نسيج "التابستري" عن

(Kirsten Glasbrook: TAPESTRY WEAVING-Search) Press.)(
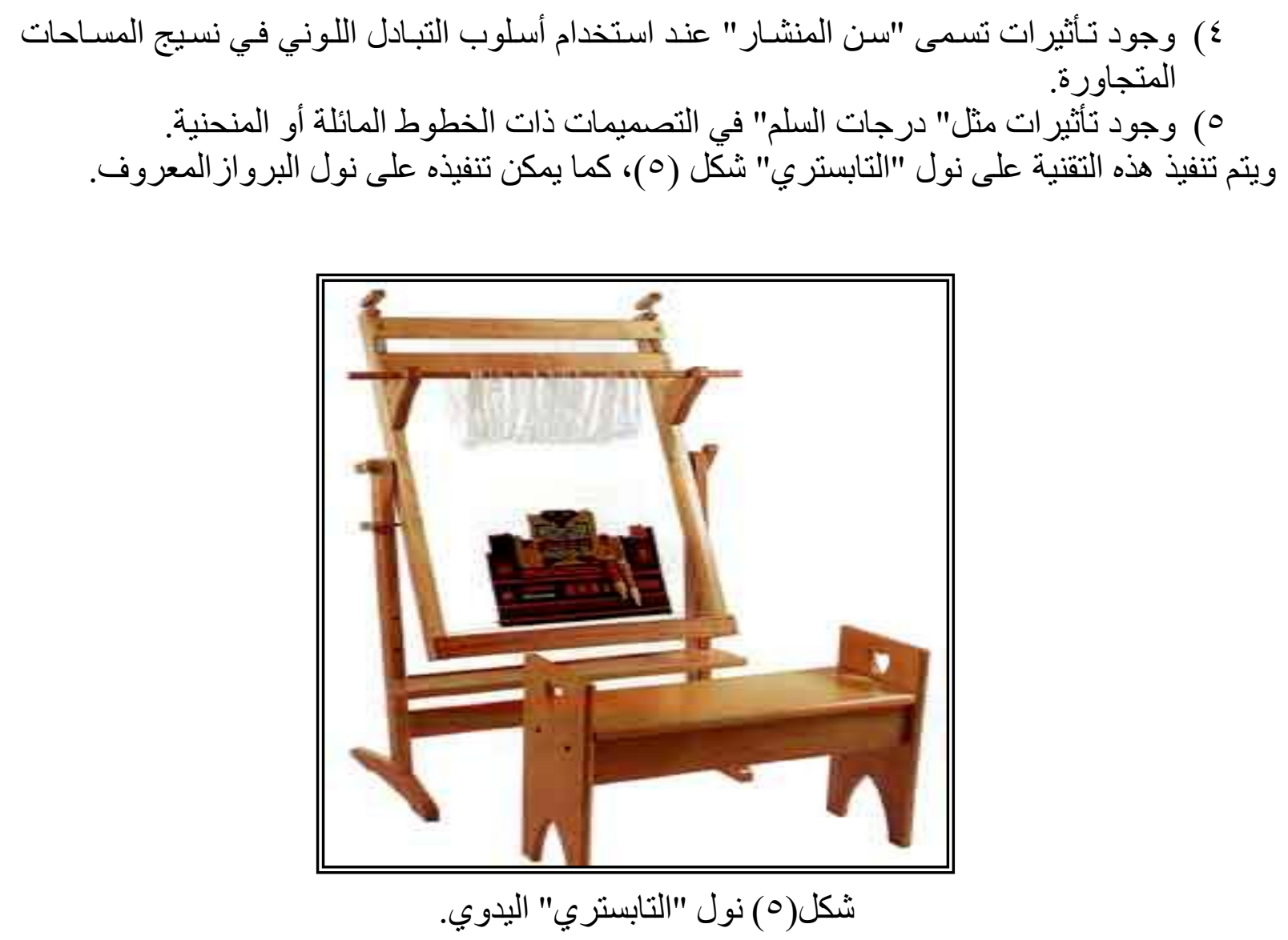

وقد تطورت المشغو لات النسجية الحديثة تطور ا كبير ا من حيث ما أستحدث فيها من تأثير ات فنيه

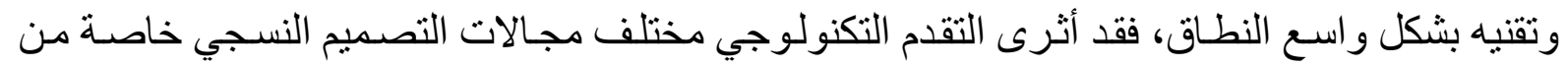




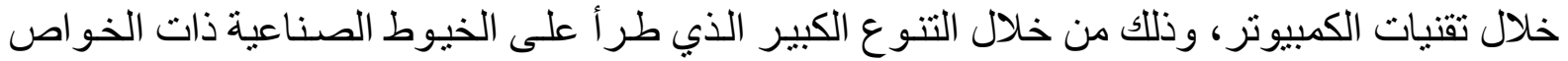

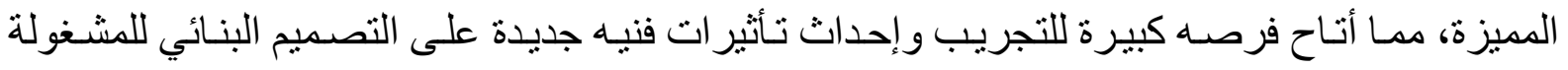

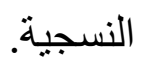

و نفذت كثير من الأعمال الفنية التشخيصية و التعبيريـة عن طريق التصميم النسجي كمـا في

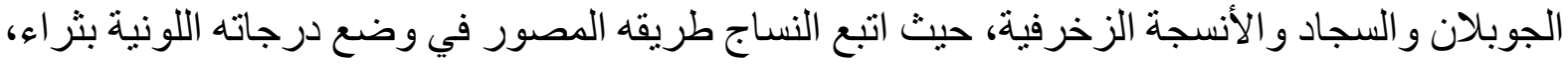

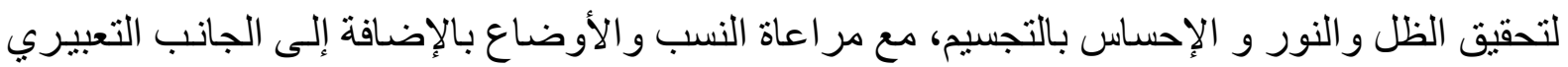

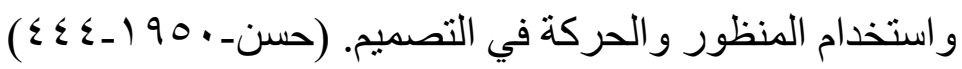

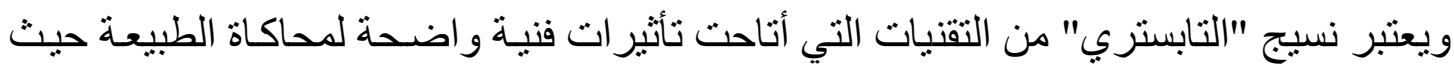

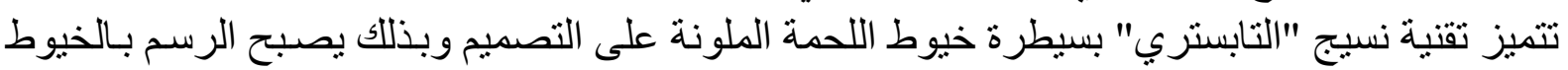
سهلاً ومعبر اً عن أدق التفاصيل ويظهر ذلك في لوحات الجوبلان و الأوبيسون التي اشتهرت بهرب بها فرنسا.

مركز النسجيات المرسمة:-

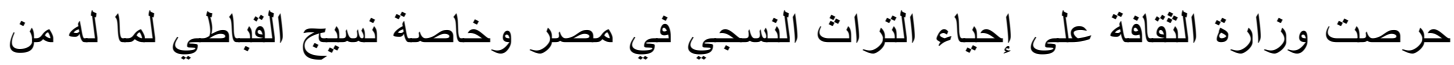

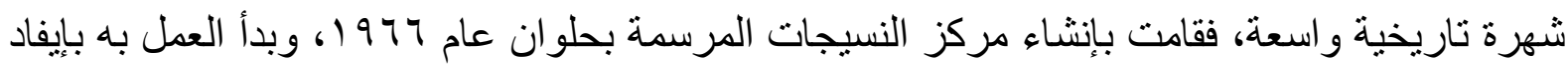

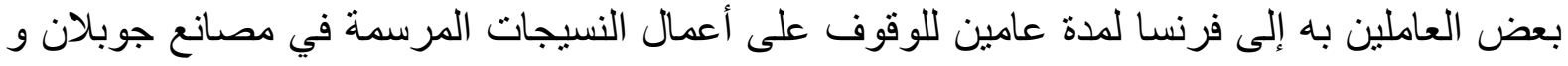

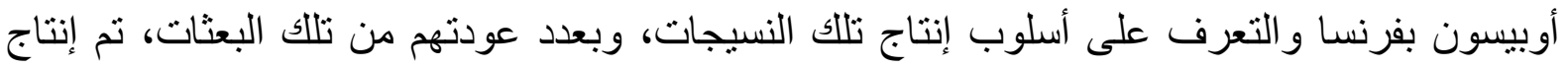

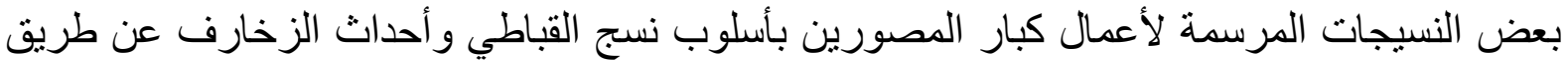

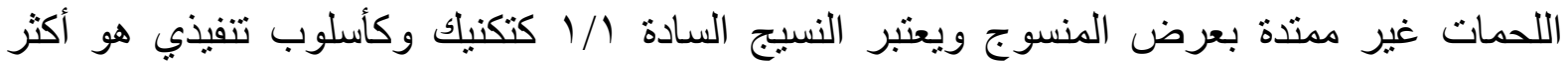

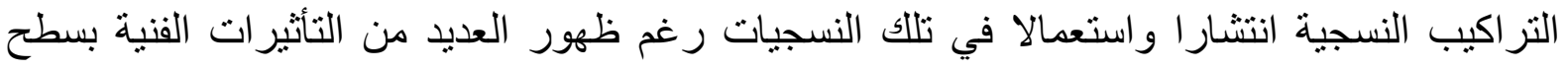
بعض أعمال النسيج المرسم في العصر الحديث.

والهذف من إنشاء هذا المركز هو إحياء فن النسيج المرسم بالمفهوم الحديث ليتمشى مع العصر

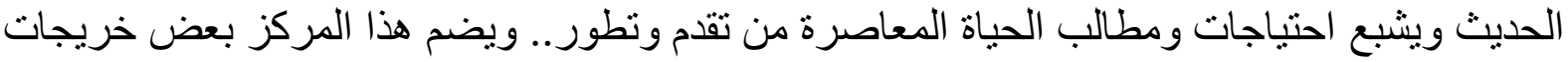

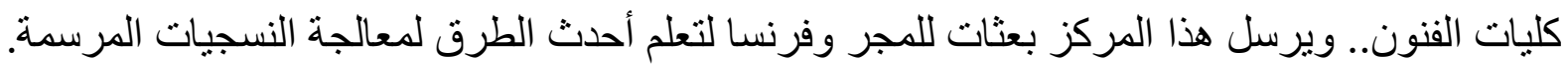
(الخو اص_-19VY)

و التربية الفنية في تكيفها مع متغير ات العصر وكسب المفاهيم الجزئية المحيطة بالفن التشكيلي

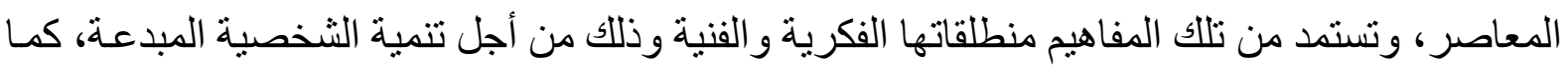

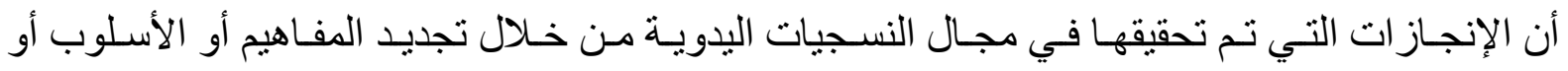

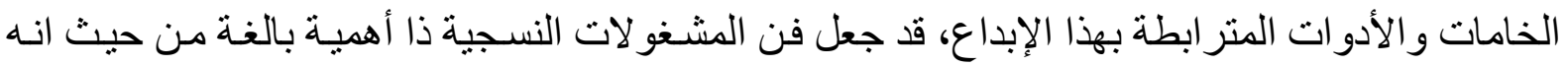
مصدر ثري بالخبر ات الفنية. 


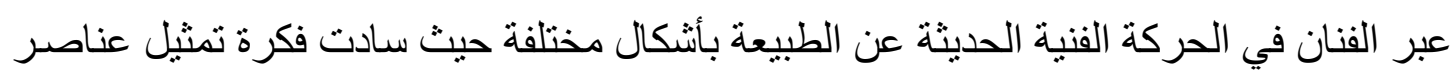

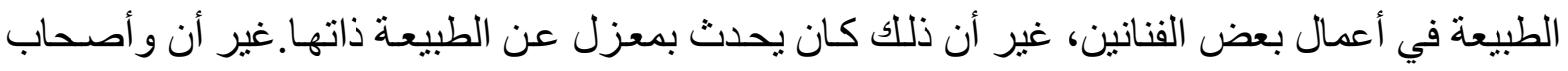

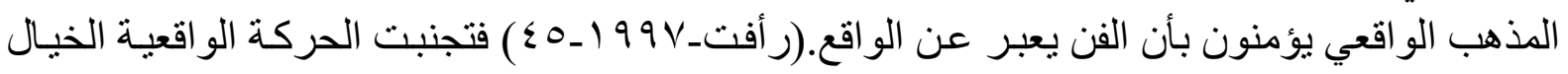

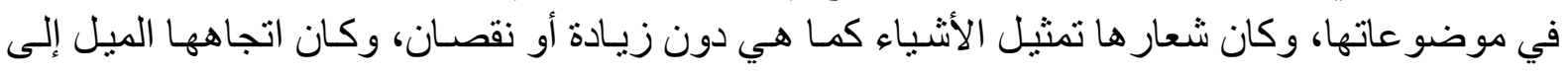

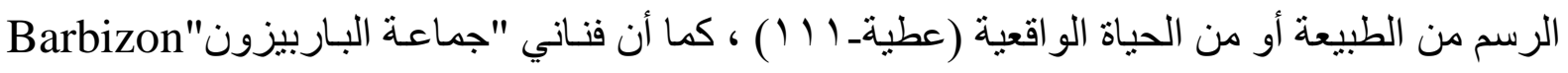

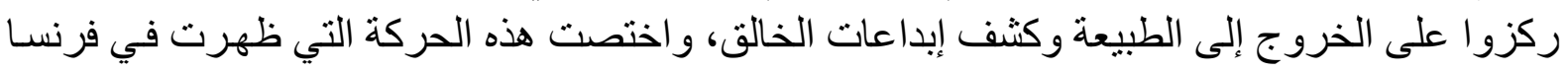

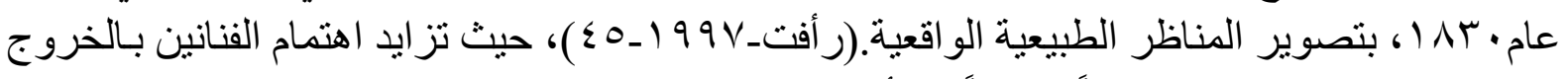

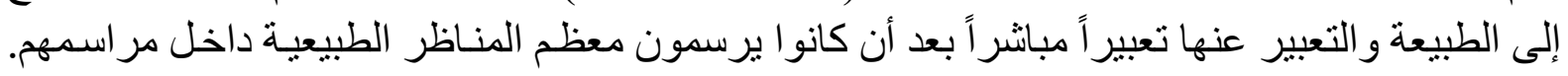

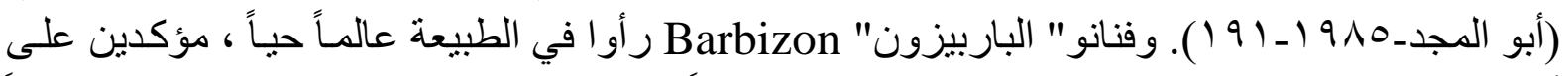

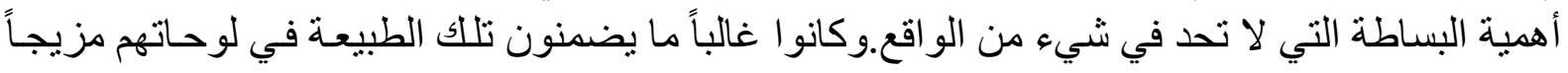

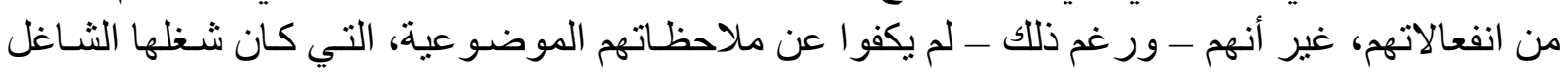

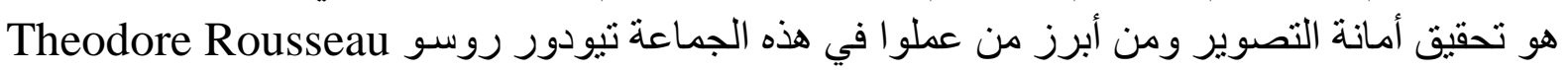

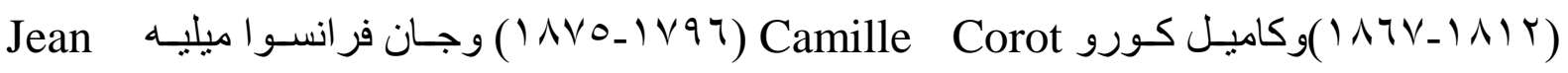

$\left(\left|\wedge \vee O_{-}\right| \wedge \mid \varepsilon\right)$ Francois Millet

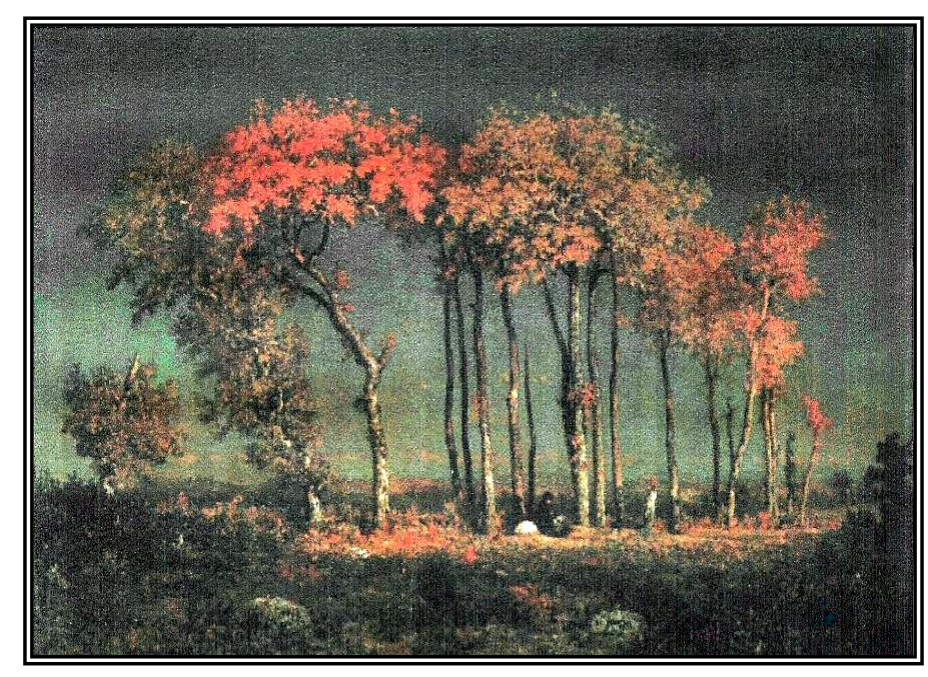

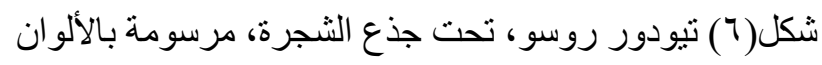

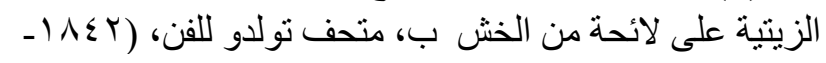

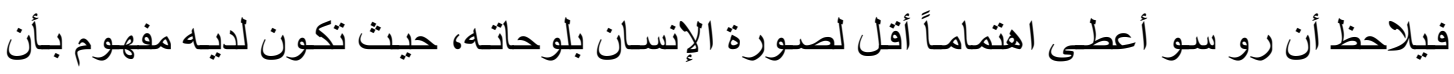

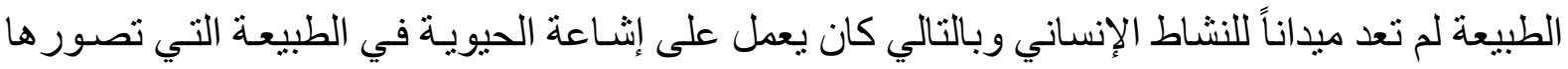

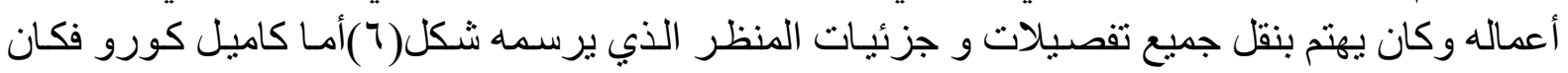

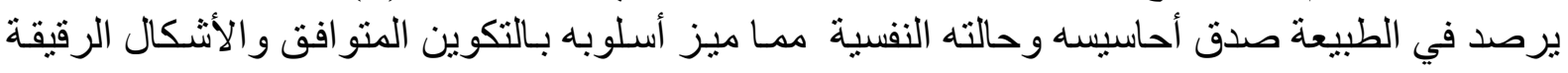

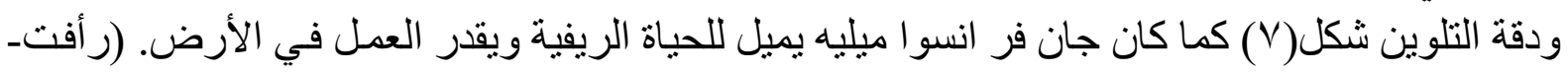
(999 999 


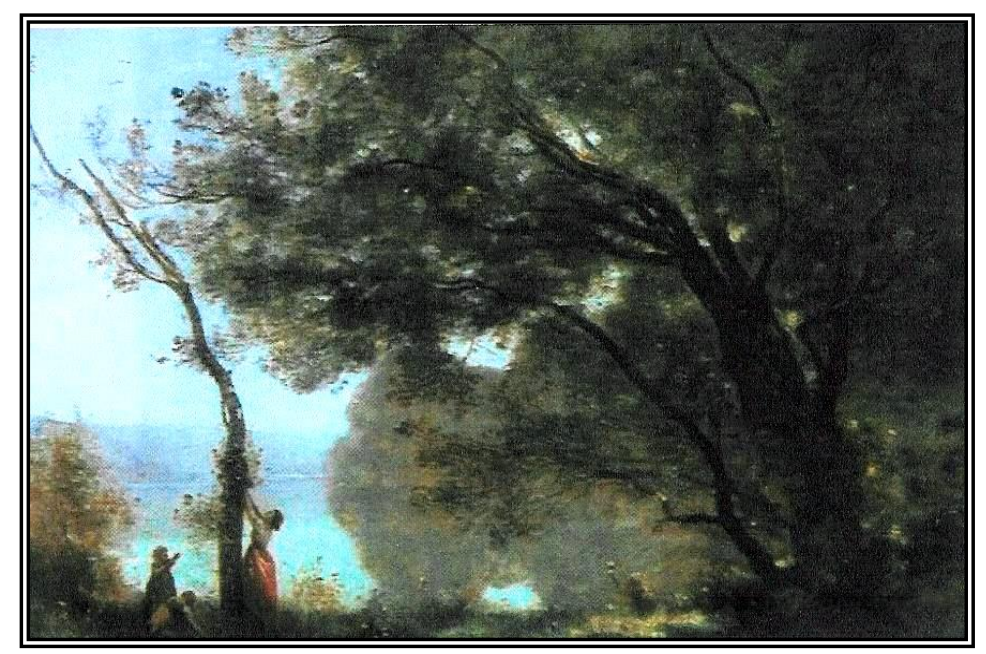

شكل(V) كاميل كورو ، منظر طبيعي، مرسومة على كانفس زيت،

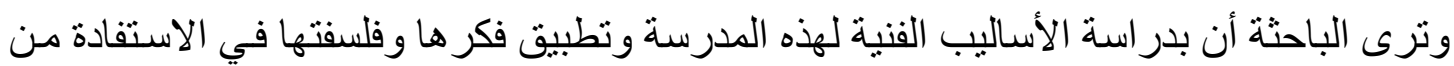

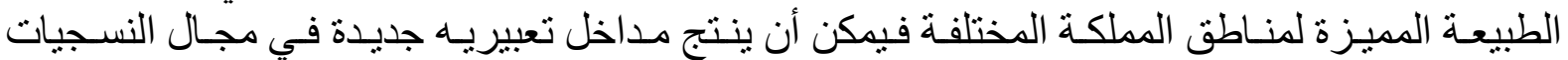

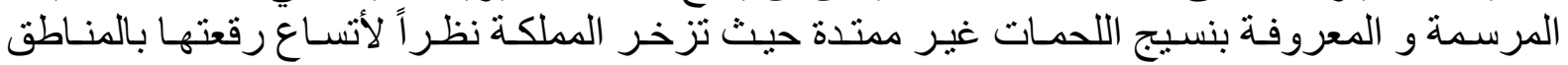
الطبيعية المختلفة بمناظر بحرية، صحر اوية، نباتية. ويمكن تلخيص هذه المداخل فيما يلي:

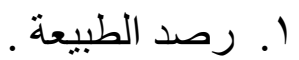
Y. ـ البعد عن القو الب الأكاديمية المألوفة، وذلك بـالانطلاق من واقع عملية التعـارف المباثـر مـع طبيعـة الموضو عات ذاتها.

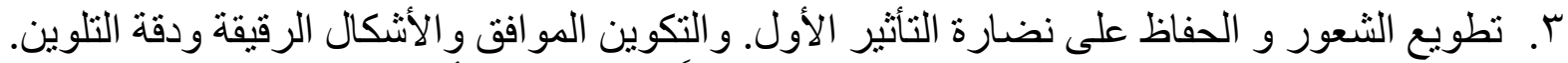

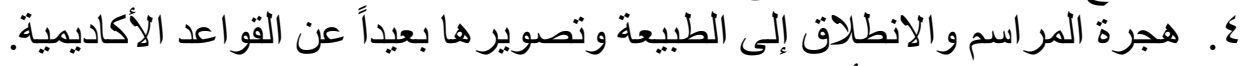
○. استخدام التظليل و الأماكن الفاتحة و الداكنة.

7. تجسيد طريقة جديدة لرؤيـة العـالم، ذوق جديد للتر ابط العميق بين الإنسـان و العـالم الطبيعي و التي لئي

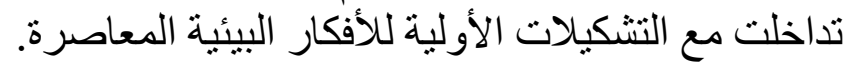

V. . إبر از التفاصيل إما باللون أو باستخدام الأضواء مما يعمل على بعث الحيوية في الألوان المعتمة التي

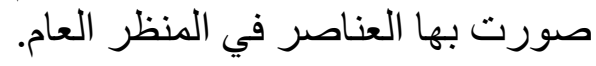


ويؤكد هذا البحث على أهمية الاستفادة من التقنيات النسجية القديمة والتي لا تز ال تستخدم بنفس التس

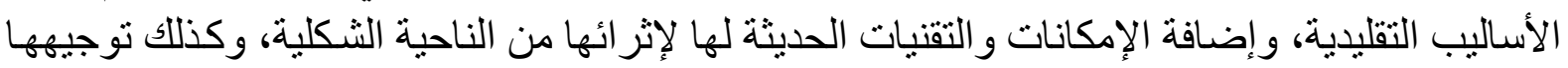
إلى مجال جديد يعتمد على توظيف الأعمال النسـية في معلقات ولوحات جداريسه وتعتمد الدارسـة على الإنى

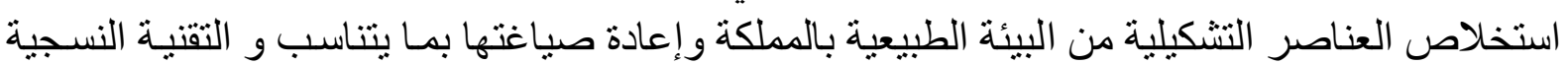

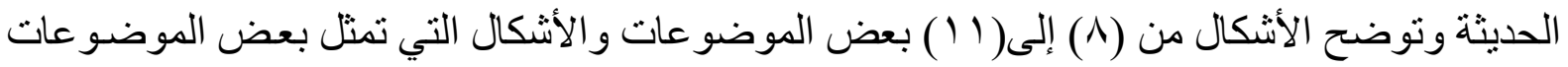

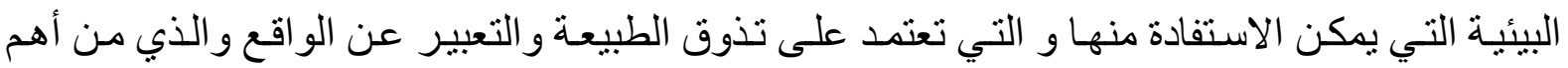

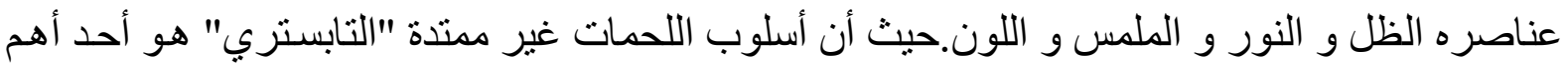

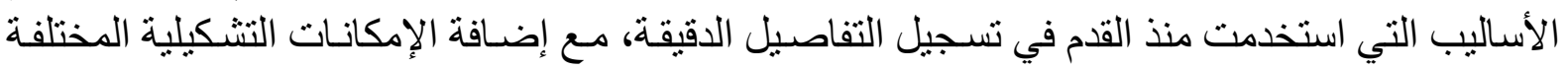
للخامات الحديثة والتي تثري العمل النسجي المرسم.

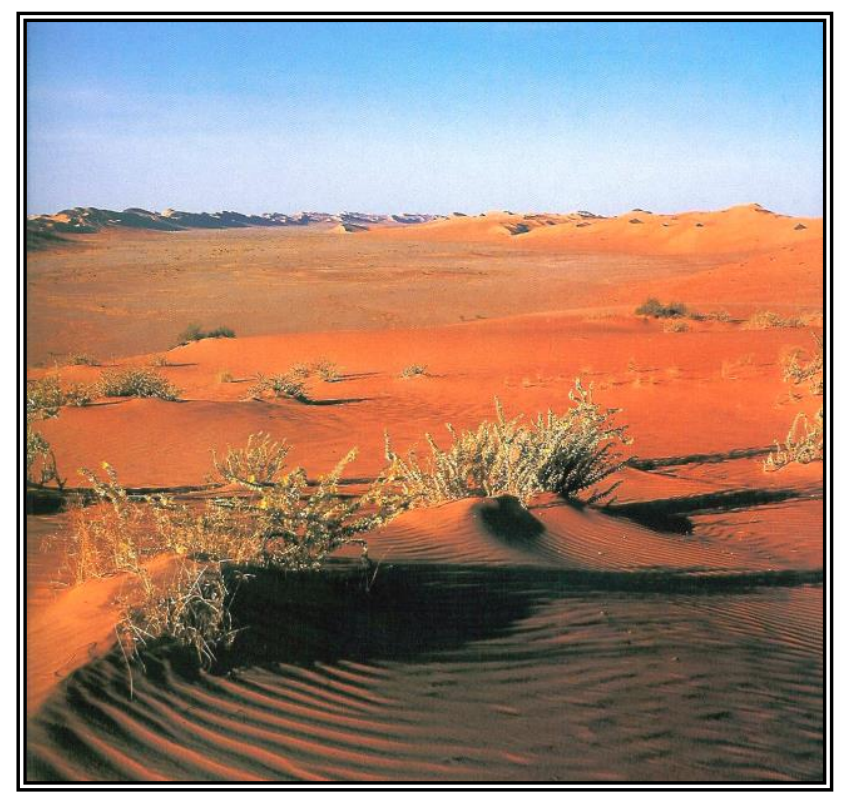

شكل(9) منظر من الربع الخالي

) Desert Images of Saudi Arabia

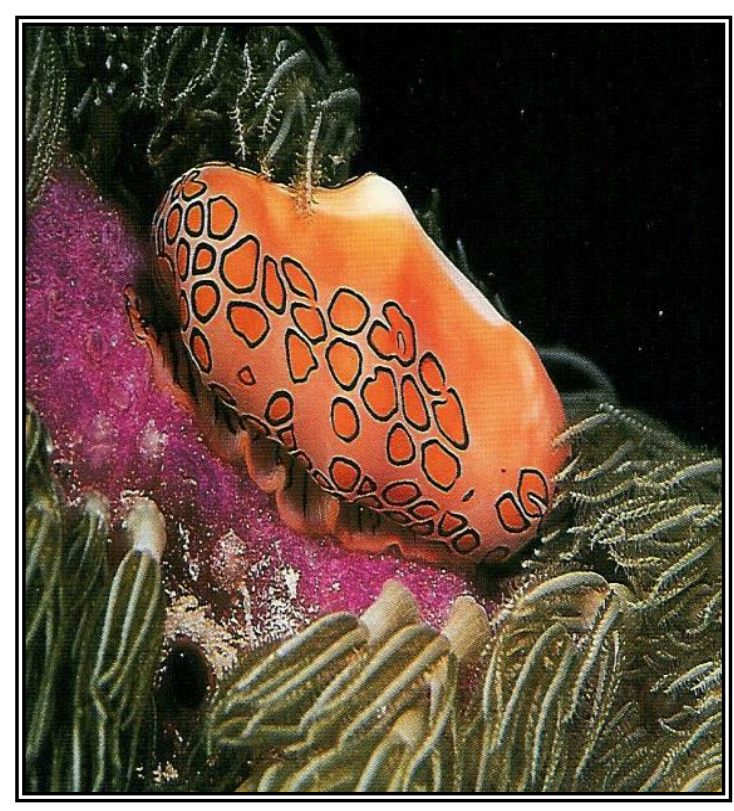

شكل(^) كائن بحري يتوسط الأعشاب المرجانية من قاع البحر الأحمر. 


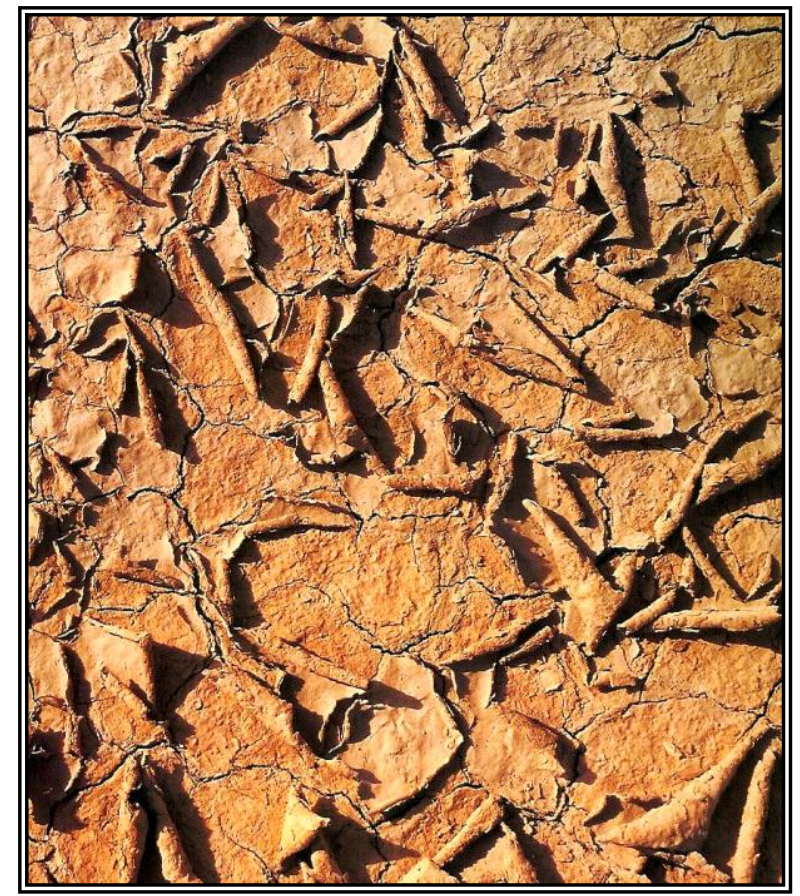

شكل (11 (1) إبداع الخالق في الطبيعة

) Desert Images of Saudi Arabia(

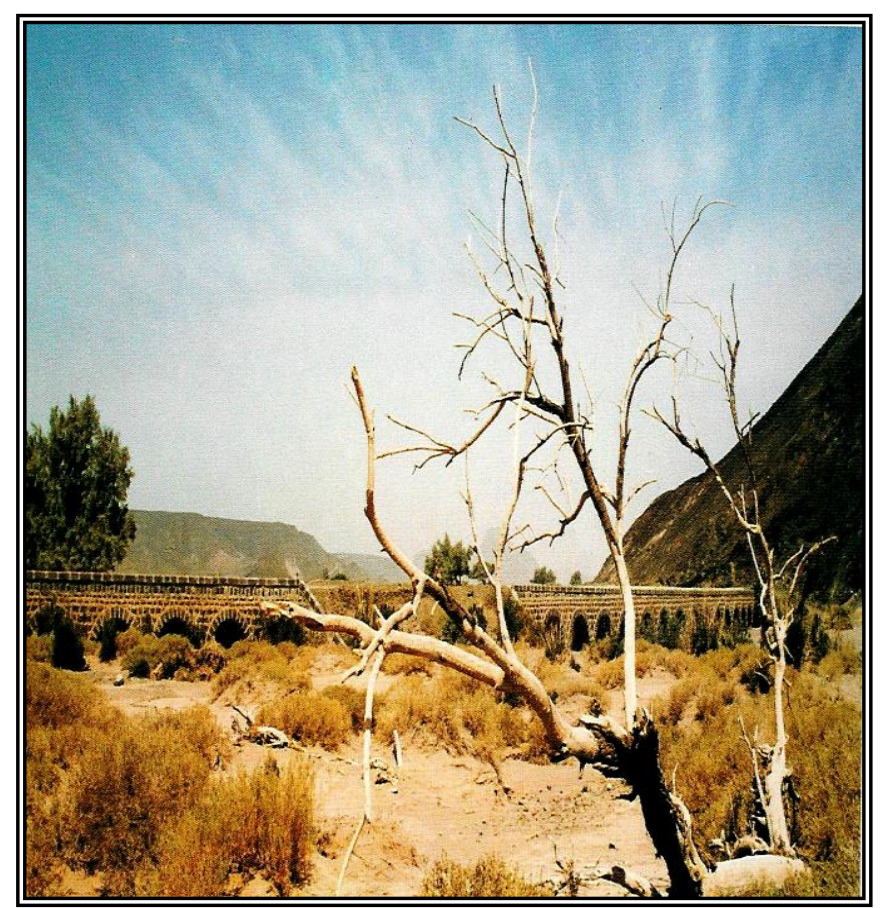

شكل(· (1) منظر منطقة بالحجاز

) Desert Images of Saudi Arabia(

وقد قامت الباحثة بعدة تطبيقات عملية للوصول الى الصياغات الفنية التشكيلية بأسلوب النسيج المرسم باستلهام من المناظر الطبيعية التي تزخر بها المملكة العربية السعودية، وفيما يلي مجموعة بلهية التطبيقات و الوصف التحليلي لها. 


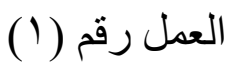

اسم العمل: تفصيل من سمكة البيغاء (الحريد)

$$
\text { الأبعاد:( • مسم × • } 7 \text { سم ) }
$$

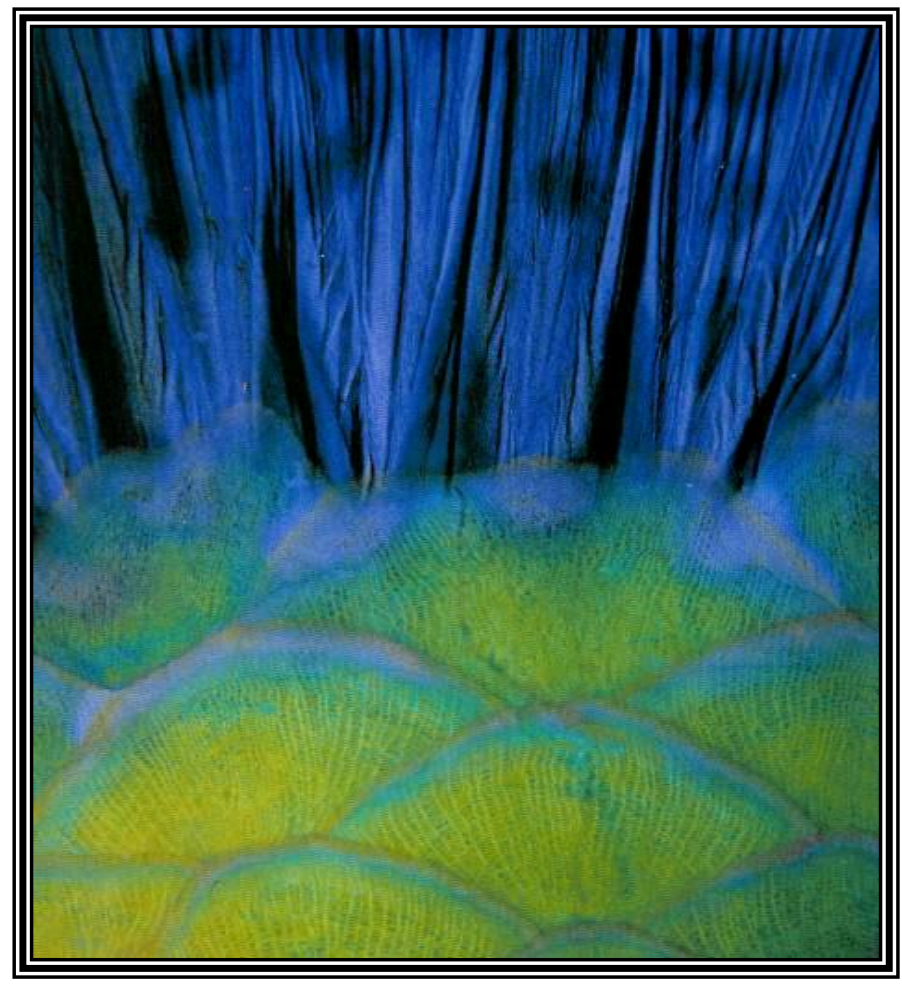

شكل (r) (1) تفصيل من سمكة البيغاء (الحريد) يركز على جزء من القثر

والزعانف.

التقنيات المستخدمة: نسيج اللحمات غير الممتدة (التابستري) - نسيج السوماك

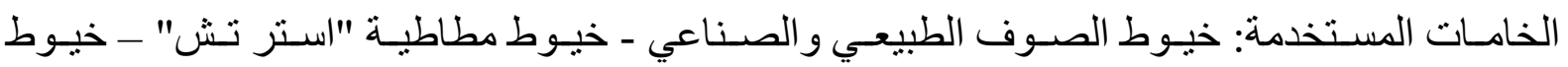

"مو هير" - خيوط ذات ملامس متنو عة (Fancy Yarns)

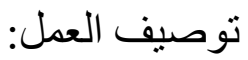

يعتمد التصميم في هذا العمل على تفصيل من سمكة البيخاء (الحريد) يركز على جز عاء من القشر

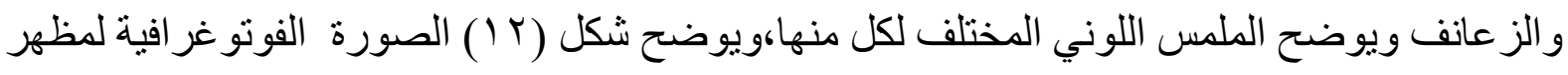

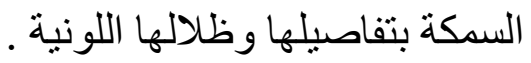




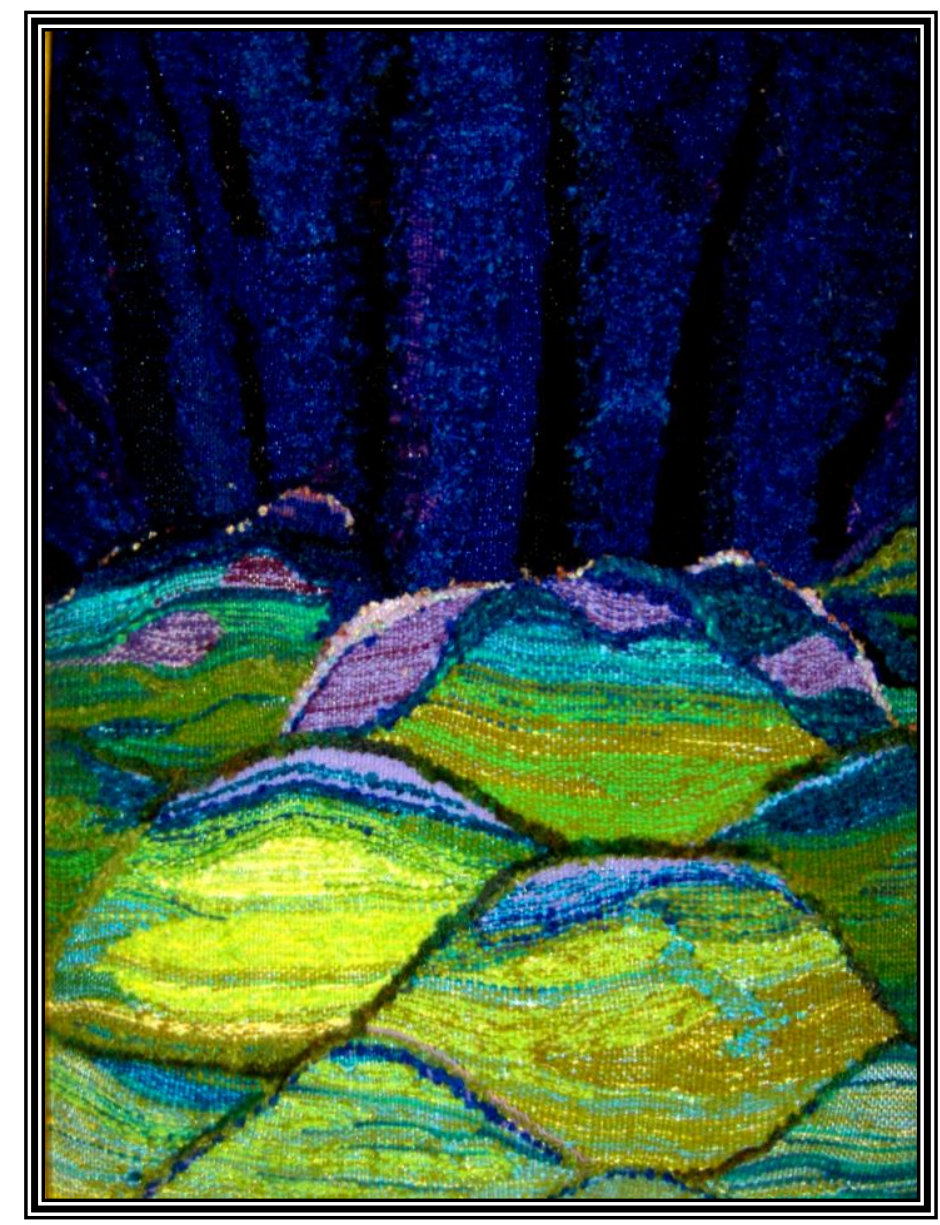

شكل (IT)

العمل النسجي

وقد قامت الباحثة بالتعبير عن القطاع التفيلي من سمكة الببغاء حيث طوعت الألوان و الخطوط إلى لعي

تأثير ات نسجية بالخيوط المتنو عة لتأكيد القيم الفنية التشكيلية والتي تتمثل في :-

أـ اللون و هو تدرجات دقيقة من اللونين الأخضر الفسفوري و الأزرق في تناغم متبادل .

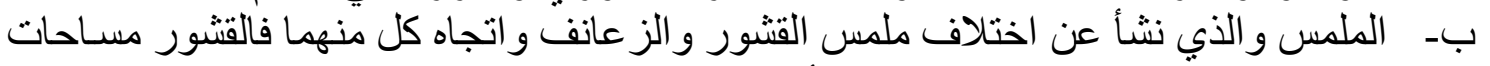

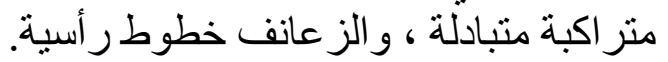

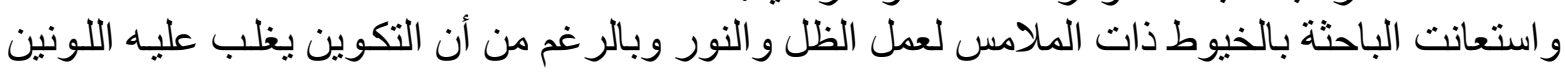

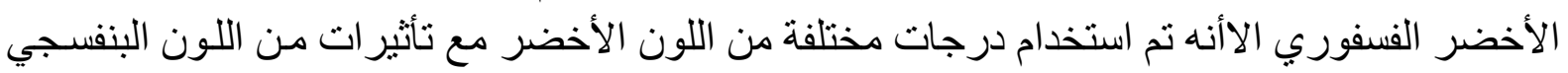

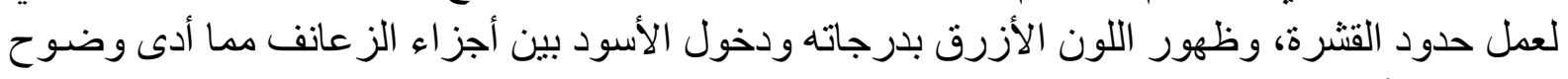

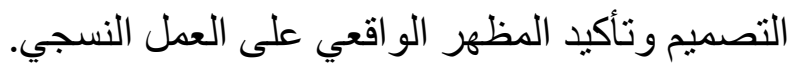

ويتميز العمل بتجسيم المساحات اللونية وذلك عن طريق إبراز خاصية الظل و النور باستخدام الخيوط

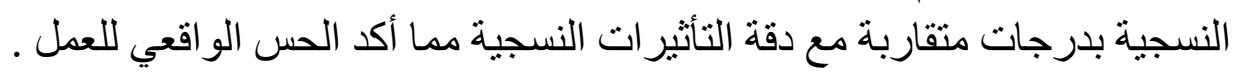
وقد أبرزت الباحثة تأثثر مدرسـة البـاربيزون في التصـوير الواقعي للعمل النسـي للحصول على أبعاد جمالية مميزة. 


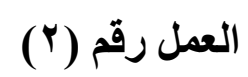

اسم العمل: نيمو بين الأعثاب المرجانية (شكل \& ( ) )

$$
\text { الأبعاد: (7 كسم × 00سم ) }
$$

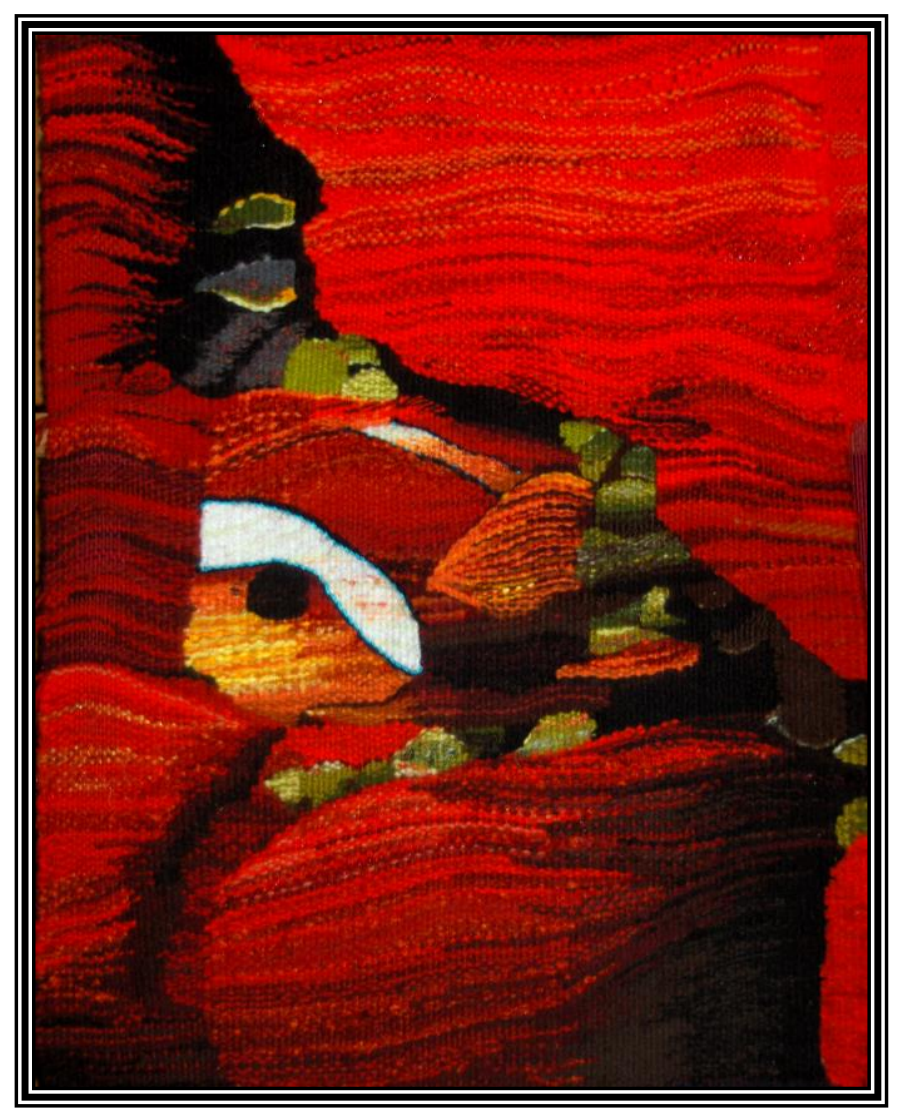

شكل ( العل (1)

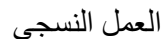




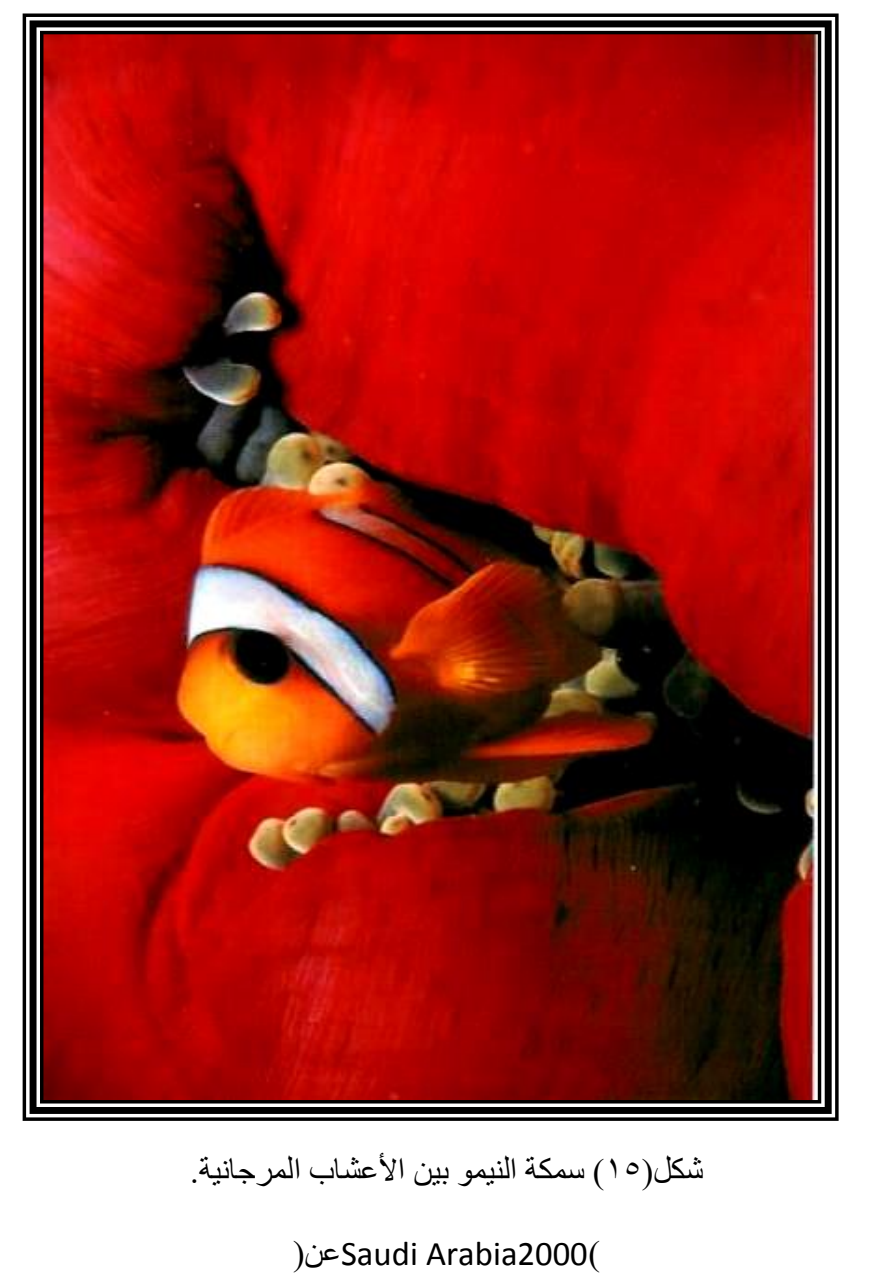

التقنيات المستخدمة: نسيج اللحمات غير الممتدة "التابستري" ـ نسيج السوماك. الخامات المستخدمة: خيوط الصوف الطبيعي و الصناعي - خيوط حرير - خيوط "مو هير" - خيوط ذات ملامس متتو عة (Fancy Yarns) توصيف العمل:

يعتمد التصميم في هذا العمل على صورة من قاع البحر شكل(0 1 ) تجمع بين الأعشاب المرجانية

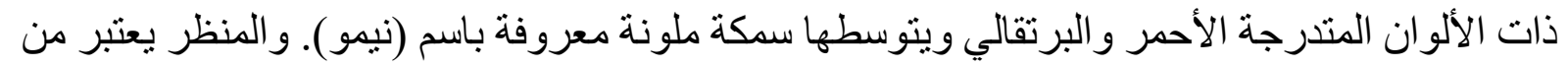
المناظر التي يزخر بها قاع البحر الأحمر. 


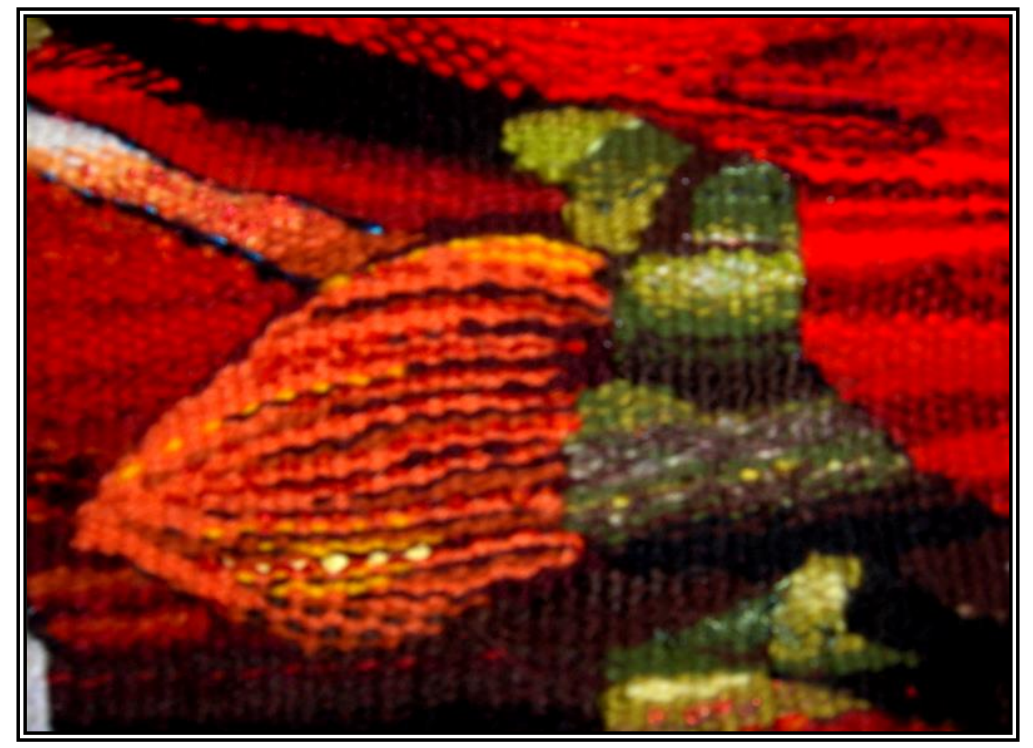

شكل( ع ( ـأ) تأثثير ات ظلية في خطوط أفقية ومائلة.

وقد قامت الباحثة بالتعبير عن المنظر الطبيعي بشكل و اقعي حيث طوعت الظلال إلى تـأثير ات

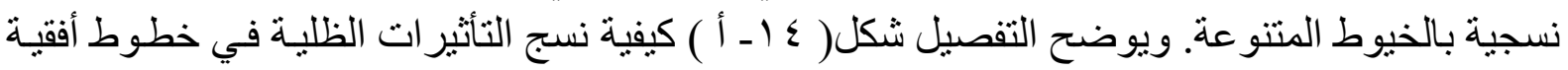
مائلة وفي تدرجات لونية منتابعة.

كمـا استعانت الباحثنة بخصـائص الخيوط ذات الملامس في وضـع إضـاءات لونيـة في التكوين

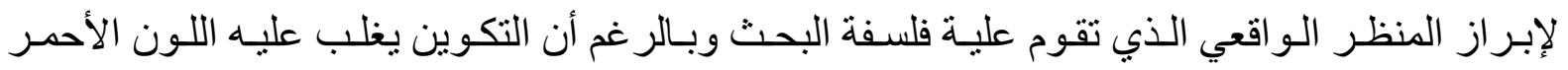

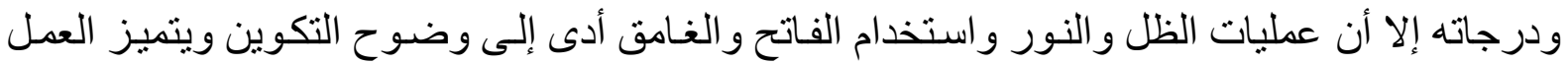
بانسيابية الخطوط اللونية التي تعطي ملمساً يساعد على تحقيق البعد الثالث الإيهامي في اللوحة.

تتمثل نتائج هذه الدر اسة في عدة نقاط تتضح من خلال الدر اسة النظرية و الممارسة العملية وهي كالتالي:ا ـ أن در اسـة الأسـاليب المميزة لمدرسـة البـاربيزون وتطبيـق فكر هـا وفلسـفتها استخدمت في اسـتلامهام موضو عات نابعة من الطبيعة المميزة لمناطق المملكة المختلفة .

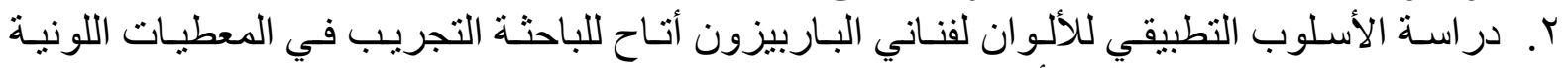

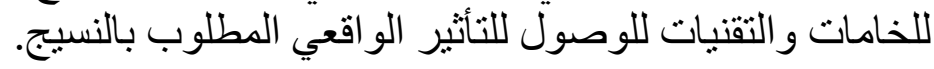

كما قامت الباحثة بالتجريب في التقنيات النسجية وخاماتها للحصول على التأثيرات التالية : 
r. الوصول إلى التدرجات اللونية باستخدام الخيوط في اتجاهات رأسية وأفقية .

ع. التدرجات الملمسية بالنسج بتقنيتي التابستري و السوماك وذلك للحصول على التأثير الو اقعي للأعمال

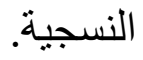

•. الحصول على تأثير ات جديدة باستخدام الخيوط الملونة للتعبير عن المنظر الطبيعي التي قامت الباحثة بتنفيذه.

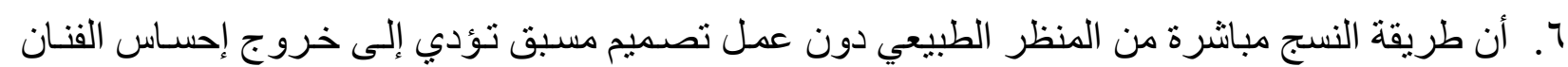

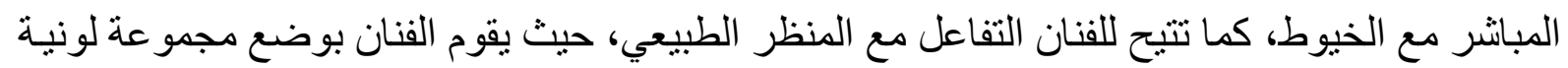

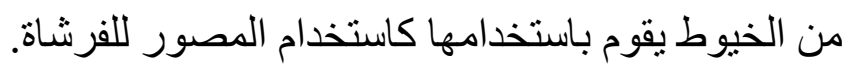

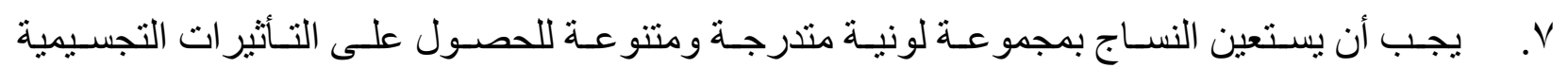

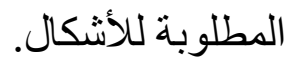

$$
\text { التوصيات:- }
$$

تتمثل توصيات الدراسة فيما يلي:

ا ـ التوسع في دراسة المدارس الفنية التي تثري المجال النسجي .

r. إنثـاء مركز أو دار خـاص بالنسـجيات المرسـة "التابستري" وتتظيم دور ات تدريبيـة في فن النسـيج المرسم وتزويده بالكفاءات المتخصصة من فنانين ونساجين وينم التدريب فيه وفق أسس ومناهج تدريبية تسمح بإنتاج قطع نسجية مرسمه تستفيد منها المؤسسات العامة و الخاصة. r. أهميـة الإسهام في تطوير فن النسـيات المرسمة "التابستري" بحيث يأخذ مكاناً بين الفنون الأخرى و الخروج عن النطاق التقليدي المتعارف عليه.

ع. التجريب في اختبار خامة اللحمة لإتاحة الفرصة في اكتثاف ملامس مبتكرة. •. إثر اء الجانب التعبيري في مجال النسيج اليدوي بالوصول إلى مداخل تعبيرية متتوعة مستوحاة من البيئة السعودية. - البران. 
ا ـ أبو المجد، علي سيد:"أساليب جديدة لاستخدامات التر اكيب النسجية في تطوير نسجيات

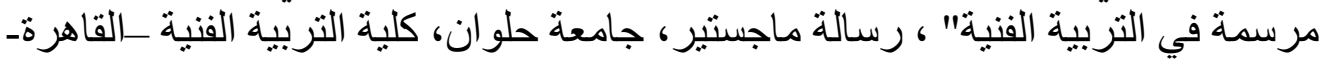

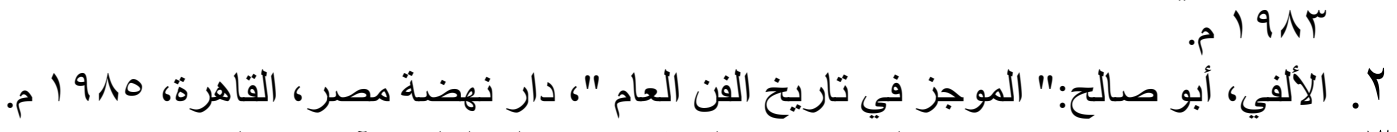

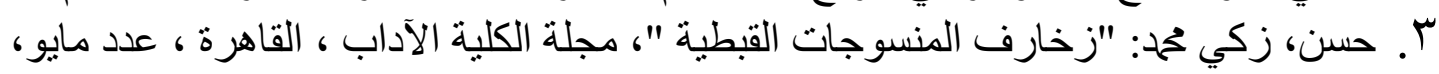

190.

ع. الخو اص، هالة عبد العزيز:" الخصائص الفنية للنسيج المرسم (القباطي) و الأصول التربوية

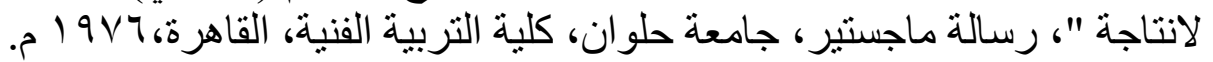

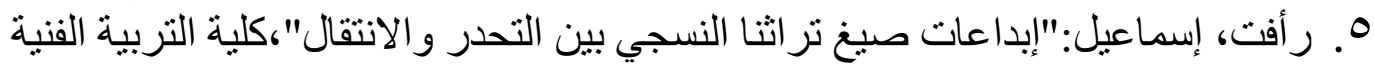

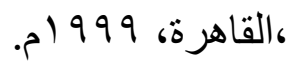

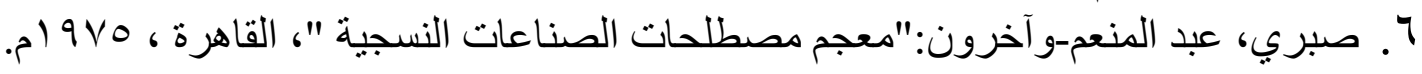

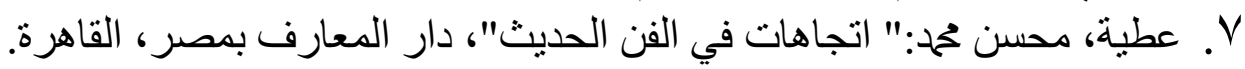

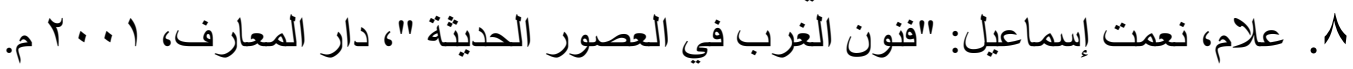

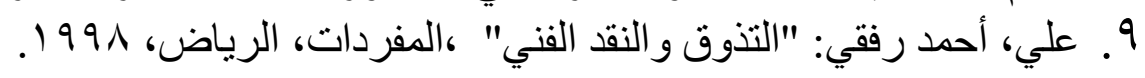

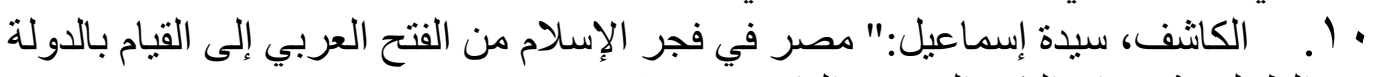

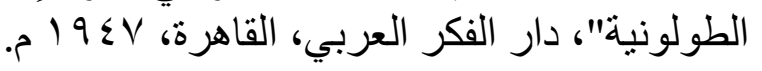

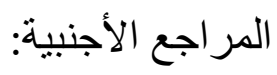

11. 58/ GLASBROOK . KIRSTEN : TAPESTRY WEAVINGSEARCH PRESS-2002

12. 65/ K.ZIPPER \& C.FRITZSCHE:ORIENTAL RUGS VOLUME4 TURKISE-1989.

13. 73/ SCHMID HAGEN: SAUDI ARABIA 2000-PRINTED AND BOUND IN SAUDI ARABIA BY JEDDAH GRAPHIC CENTER1999.

14. 92/ http://www.abestoilpainting.com/corot/2005

15. 93/http://www.artprintgdemand.com.uk/noframes/millet/thumbs.ht $\mathrm{m} 2005$

16. 94/ http://www.arbworldbooks.com/readers 2002

17. 95/ http://www.albayan.co.ac/albayan/200/mnw30.htm t/becquiny .jpg.html.2005

18. 96/ http://www.bab.com/articles/full-article.cfmid=6007 